International Journal of Automotive and Mechanical Engineering (IJAME)

ISSN: 2229-8649 (Print); ISSN: 2180-1606 (Online);

Volume 13, Issue 2 pp. 3278 - 3292, September 2016

CUniversiti Malaysia Pahang Publishing

DOI: https://doi.org/10.15282/ijame.13.2.2016.1.0273

\title{
Numerical investigation of maximum air entrainment into cylindrical louvered pipe
}

\author{
Sameer Ranjan Sahu and Dipti Prasad Mishra* \\ Department of Mechanical Engineering, Birla Institute of Technology \\ Mesra, Ranchi - 835215, India \\ *Email: dpmishra@bitmesra.ac.in \\ Phone: +91-7250582643
}

\begin{abstract}
The main approach behind the present numerical investigation is to estimate the air flow rate into the pipe through the louvers from the atmosphere. The present numerical investigation has been performed by solving conservation equations of mass, momentum, and energy along with two equation-based k- $\varepsilon$ models for a louvered horizontal cylindrical pipe by the finite volume method. The existing experimental results of a wall constraint jet have been matched with the numerical results. The numerical computations show that the air suction rate into the pipe increased with the increase in the louvers opening area and number of nozzles used. With all other parameters remain fixed, an optimum protrusion of the nozzle was found where the suction rate was found to be the highest for a given nozzle flow rate. It was also found from the numerical investigation that there exists an optimum pipe diameter corresponding to the three times of nozzle diameter where the maximum air suction rate was achieved.
\end{abstract}

Keywords: entrainment; louvers; nozzle; exhaust gas; horizontal pipe

\section{INTRODUCTION}

The exhaust system of a vehicle releases hot gasses directly into the atmosphere. The hot exhaust gasses (temperature of about $70-90^{\circ} \mathrm{C}$ ) give rise to many environmental problems as well as respiratory diseases. Due to the direct release of the hot exhaust gasses, the local environmental temperature is rising every day causing adverse climatic changes thereby making it difficult for every organism to survive on the planet. These problems are very acute in the metro cities during rush hours when the vehicles are temporarily stopped at the crossings due to traffic problems. The hot exhaust smoke coming from the vehicles with a high-velocity may cause very serious problems specifically in the respiratory systems of the two wheeler passengers and pedestrians. If some new techniques are applied to cool down the exhaust gasses, then it is possible to control the increasing rate of the local surrounding temperature. The cooling and reduction in the velocity of the exhaust gasses can be effectively achieved by sucking fresh air from the atmosphere through the louver cut on the periphery of pipe without using any extra power from a pump. The high-speed gas coming out of the nozzle as shown in Figure 1 creates a low pressure inside the pipe that is used to suck atmospheric air into the pipe to cool down the gas. By achieving sufficient cooling of the exhaust gas, the increasing rate of the local environmental temperature is controlled so that the adverse effect due to hightemperature vehicle emission can be minimised. 


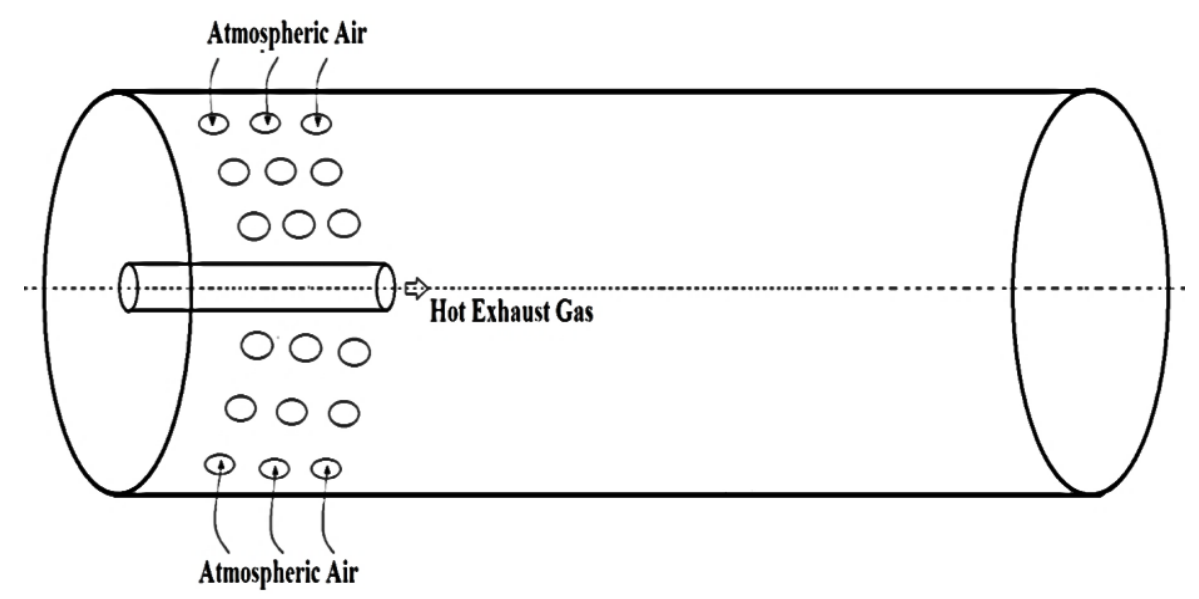

Figure 1. Atmospheric air sucked into the pipe.

Considerable research work has been performed for cooling down the exhaust emissions and reducing the environmental pollution. Ricou and Spalding [1] described a new technique for measuring the axial mass flow rate formed by the turbulent jet when a gas is injected into a reservoir of stagnant air at uniform pressure. They found that the new technique for measuring the entrainment rate was applicable to jets of non-uniform density. They also found that the entrainment rate was increased by $30 \%$ when the injected gas burned in the jet. Hill [2] conducted an experiment to measure the local entrainment rate in the initial region of axisymmetric turbulent air jets. He found that the local entrainment rate was independent of the nozzle Reynolds number for values more than $6 \times 10^{4}$ and strongly depending on the axial distance from the injection site. He concluded that the entrainment coefficient increased with the axial distance in the initial region and became almost constant in the fully developed region.

Han and Mungal [3] studied the entrainment of the turbulent jet in co-flow, with and without reaction by directly using Particle Image Velocimetry (PIV) for measurement. They found that the increase in the co-flow speed reduced the entrainment for both the reacting and non-reacting jets. They found that the entrainment in the near field of reacting jets was reduced by a factor of 2.5 due to the heat release effect. They also found that the effect of buoyancy increased the entrainment thereby compensating for the heat release effect in the reacting jet. Singh, Sundararajan [4] conducted an experimental investigation on the entrainment characteristics of the confined and semiconfined circular and noncircular jets. They found that the non-circular jets provided greater entrainment and mixing with ambient fluid than the circular jets. They also found that the entrainment ratio for all the non-circular jets was more compared to a circular jet. They concluded that by shifting the location of the jet, the entrainment was enhanced by $30 \%$. DP Mishra et. al, [5, 6] conducted a numerical investigation on the air entrainment into a mixing tube due to the high-velocity isothermal jet and concluded that the air suction rate was enhanced with the increase in the louvers opening area but independent of number of louvers per row. They also concluded that keeping the total cross-sectional area and nozzle flow rate constant, the use of multiple nozzles had no effect on the air suction rate. They also found that to get the maximum air suction effect, the protruding length of the nozzle was found to be around $0.5 \mathrm{~m}$ from the bottom wall of the funnel. They also predicted the entrance length and mass suction rate for a cylindrical funnel. They found that the ratio of funnel diameter to the nozzle diameter had the highest effect on the mass suction rate. Barik, Dash [7] did an experimental and numerical investigation 
similar to Mishra and Dash [5] to study the flow recirculation in the suction zone. They concluded that at a particular Reynolds number, the entrainment rate of the hot fluid is more than the cold fluid due to buoyancy. They found that the entrainment was increased with the nozzle protruding length irrespective of the fluid temperature. They also concluded that the entrainment was enhanced by $70 \%$ when the louver opening area was increased from 116.7 to 584 . They found this result when the ratio of nozzle inlet temperature and ambient temperature was 1.19. Singh [8] used a finite element model for predicting the level of entrainment and mixing in a confined turbulent jet of variable density. They achieved the turbulence closure by the modified Prandtl mixing length model. They found that the ratio of tube and inlet jet diameters along with the ratio of free stream air density to the density of air at jet inlet condition were the main factors influencing the entrainment and mixing. They also found that moving the jet away from the tube inlet increased the entrainment for short distances but reduced the entrainment for long distances.

Mishra, Dash [9] also studied the effect of high-velocity isothermal air jet placed inside the funnel having different lengths of the protrusion and different funnel diameters. They concluded that for isothermal air suction the mass ingress into the funnel did not depend on the inclination of the funnel but for a low-velocity and high temperature of the nozzle fluid the mass ingress into the funnel depends on the inclination of the funnel. They also found from the experimental and CFD computation that there existed an optimum funnel diameter and protrusion length of the nozzle for maximum air flow into the funnel. Barik et al. [10-12] conducted an experimental and numerical investigation on air entrainment in the infra-red suppression device. They used both circular and noncircular nozzles to carry out the analysis. They found that the nozzle aspect ratio was an important factor for entrainment. The entrainment rate was found to be enhanced by $44 \%$ when the nozzle aspect ratio was increased from 0.846 to 1.6. They concluded that the mass entrainment decreased as the nozzle moved away from the bottom funnel. They found that the entrainment rate was reduced by $19.2 \%$ as the ratio of funnel overlap height and nozzle diameter changed from 0 to 1.6. In their research, they found new correlations for air entrainment into infra-red suppression device to predict the funnel outlet temperature and mass entrainment into IRS device. They also found that the funnel overlap height was the most significant parameter for entrainment. Mishra and Dash [13] conducted a similar numerical investigation to find the optimum design for the maximum air suction into the louvered funnel and found that an inverted frustum with a diameter ratio of 0.8 could suck the maximum amount of air compared to a cylindrical funnel of the same volume.

Andwari, Aziz [14] conducted an experimental analysis on a controlled autoignition two-stroke engine to see the effects of burned-gas utilization on the concentration of exhaust gasses. They found that by increasing the percentage of recirculation of the exhaust gasses, NOx concentrations can be reduced. Akasyah, Mamat [15] used various alcohols as biofuels for running the four-stroke diesel engine simulations. They found that diesel had the highest heat release as compared to other alcohol fuels. It was also concluded that the high inlet air temperature led to the low engine performance. Hamada and Rahman [16] conducted an experimental analysis to study the performance and emissions of a spark-ignited, port-injected, gasoline-fuelled, water-cooled and small-size modern motorcycle engine. They found that implementing an electronically-controlled port injection for a gasoline engine as a base for a lightweight high-speed motorcycle was highly successful. They suggested by using the concept of a dual-fuel engine which has tremendous potential for the performance enhancement and emission reduction. CFD 
analysis of a hydrogen fuelled internal combustion engine was performed by Hamada KI [17] to study the flow field characteristics of the in-cylinder engine. They revealed that the volumetric efficiency increases with engine speed. The results obtained from the simulation can be employed to examine the homogeneity of the air-fuel mixture for better combustion and engine performance. Mohd Noor CW [18] predicted the output torque, brake power, brake specific fuel consumption and exhaust gas temperature of a marine diesel engine using the artificial numerical network. The predicted data set of the model was compared with the measured experiment data. The results showed that the ANN model has a good agreement with the experimental data. The prediction error in the ANN model was low compared to the mathematical model.

The work found in the literature did not cite the use of CFD methods to determine the effect of various parameters on the mass suction rate of air into a horizontal louvered pipe for a vehicle and hence, the present work is done to arrive at the optimum design of the pipe by investigating the fluid flow and heat transfer characteristics. The study was carried out assuming the exhaust pipe as the nozzle and hot air as the nozzle fluid and the flow was treated to be incompressible. The researchers have attempted to match the existing experiment results of Singh, Sundararajan [4] with the present computational methods. The present numerical research studies the effect of different parameters on maximum air suction when the atmospheric air enters the pipe only through the louvers cut on it.

\section{MATHEMATICAL FORMULATION}

A cylindrical pipe of diameter $D_{P}$ and length $L_{P}$ (shown in Figure 2) was used to carry out the computational investigation. The pipe was closed at the entrance and its exit opened to the surrounding atmosphere. A nozzle of diameter $\mathrm{D}_{\mathrm{n}}$ having a protrusion length $\mathrm{L}_{\mathrm{Pt}}$ (into the pipe) was located at the centre of the bottom face of the pipe. Hot air was supplied by using this nozzle. A cylindrical computational domain of diameter $\mathrm{D}_{\mathrm{CD}}$ (about 6 times of $D_{P}$ ) and length $L_{C D}$ (about 3 times of $L_{P}$ ) was placed around the pipe so that the boundary conditions can be applied on the computational domain for the air to be sucked in by the louvers in the pipe. The louvers were made in a circular shape $\left(D_{h}=0.03 \mathrm{~m}\right)$. A total of 12 louvers were placed in each stack with a distance of $0.05 \mathrm{~m}$ being maintained between each stack. The first stack of louvers was at a distance of $0.3 \mathrm{~m}$ from the bottom of the pipe. The number of rows of louvers used in the pipe varied from 8 to 9 . The flow field of the domain was computed by using three-dimensional, incompressible NavierStokes equations and a standard two equation $k-\varepsilon$ turbulence model with energy equation. The $\mathrm{Re}_{\mathrm{n}}$ (Reynolds number based on the nozzle diameter) varied from $2.4 \times 10^{4}$ to $2.6 \times$ $10^{4}$. The fluid used for simulation was air at $343 \mathrm{~K}$ with a mass flow rate of $0.02 \mathrm{~kg} / \mathrm{s}$ at the nozzle outlet and the flow was treated to be incompressible. The values of mass flow rate and temperature for exhaust gas were taken from the Petter Kirloskar Diesel CI Engine having the following specifications: $10 \mathrm{hp} 1500 \mathrm{rpm}$, twin cylinder vertical 4 strokes, compression ratio $16.5: 1$, bore $80 \mathrm{~mm}$, stroke $110 \mathrm{~mm}$, exhaust pipe diameter $5 \mathrm{~cm}$. Steel was used as the solid material for all the walls defined for the present numerical study. 


\section{Governing Equations}

The governing equations used for the present analysis can be written as:

Continuity equation:

$$
\frac{\partial}{\partial x_{i}}\left(\rho U_{i}\right)=0
$$

Momentum equation:

$$
\begin{gathered}
\frac{D\left(\rho U_{i}\right)}{D t}=-\frac{\partial p}{\partial x_{i}}+\frac{\partial}{\partial x_{j}}\left[\mu\left(\frac{\partial U_{i}}{\partial x_{j}}+\frac{\partial U_{j}}{\partial x_{i}}\right)-\overline{\rho u_{j} u_{j}}\right] \\
\frac{p}{\rho}=R T
\end{gathered}
$$

The density $\rho$ was taken as the function of temperature according to the ideal gas law as per Eq. (3), while the dynamic viscosity $\mu$ and thermal conductivity were kept constant.

Energy equation:

$$
\frac{D(\rho \mathrm{T})}{D t}=\frac{\partial}{\partial x_{i}}\left[\left(\frac{\mu}{\operatorname{Pr}}+\frac{\mu_{t}}{P r_{t}}\right) \frac{\partial T}{\partial x_{i}}\right]
$$

Turbulence kinetic energy, $k$ :

$$
\frac{D}{D t}(\rho \mathrm{k})=D_{k}+\rho P-\rho \varepsilon
$$

Dissipation rate of turbulent kinetic energy, $\varepsilon$ : [13]

$$
\begin{gathered}
\frac{D}{D t}(\rho \varepsilon)=D_{\varepsilon}+C_{1 \varepsilon} \rho P \frac{\varepsilon}{k}-C_{2 \varepsilon} \rho \frac{\varepsilon^{2}}{k} \\
\overline{u_{i} u_{j}}=\frac{2}{3} k \delta_{i j}-v_{t}\left(\frac{\partial U_{i}}{\partial x_{j}}+\frac{\partial U_{j}}{\partial x_{i}}\right): v_{t}=0.09 \frac{k^{2}}{\varepsilon} \\
D_{\phi}=\frac{\partial}{\partial x_{j}}\left[\left(\mu+\frac{\mu_{t}}{\sigma_{\phi}}\right) \frac{\partial \phi}{\partial x_{j}}\right] \\
P=-\frac{u_{i} u_{j}}{\partial U_{i}}
\end{gathered}
$$

where $\sigma_{\mathrm{k}}$ and $\sigma_{\varepsilon}$ are the Prandtl numbers for $\mathrm{k}$ and $\varepsilon$.

$\mathrm{R}$ is the characteristic gas constant and equal to $0.287 \mathrm{~kJ} / \mathrm{kg}-\mathrm{K}$.

The following constants were used in the $\mathrm{k}-\varepsilon$ equations

$\mathrm{C}_{1 \varepsilon}=1.44, \mathrm{C}_{2 \varepsilon}=1.92, \mathrm{C}_{\mu}=0.09, \sigma_{\mathrm{k}}=1.0, \sigma_{\varepsilon}=1.3, \mathrm{Pr}_{\mathrm{t}}=1$.

Although these constants were normally used for internal flows they have not been changed for the present case of mixed flows i.e. both internal and external.

\section{Boundary Conditions}

The boundary conditions for the louvered pipe are shown in Figure 2. The pipe and nozzle walls were solid and a no-slip boundary condition was imposed. The pressure outlet boundary condition was given to the top, side and bottom surface of the computational 
domain. The nozzle outlet was given velocity inlet and temperature boundary condition to supply hot air into the pipe. The velocity was computed from the local pressure field to satisfy the continuity of the pressure outlet boundary while all the other variables like $\mathrm{T}, k$, and $\varepsilon$ were computed from zero gradient condition. The turbulent intensity at nozzle inlet was set to $2 \%$, while $5 \%$ was set for back-flow turbulent intensity at all pressure outlet boundaries.

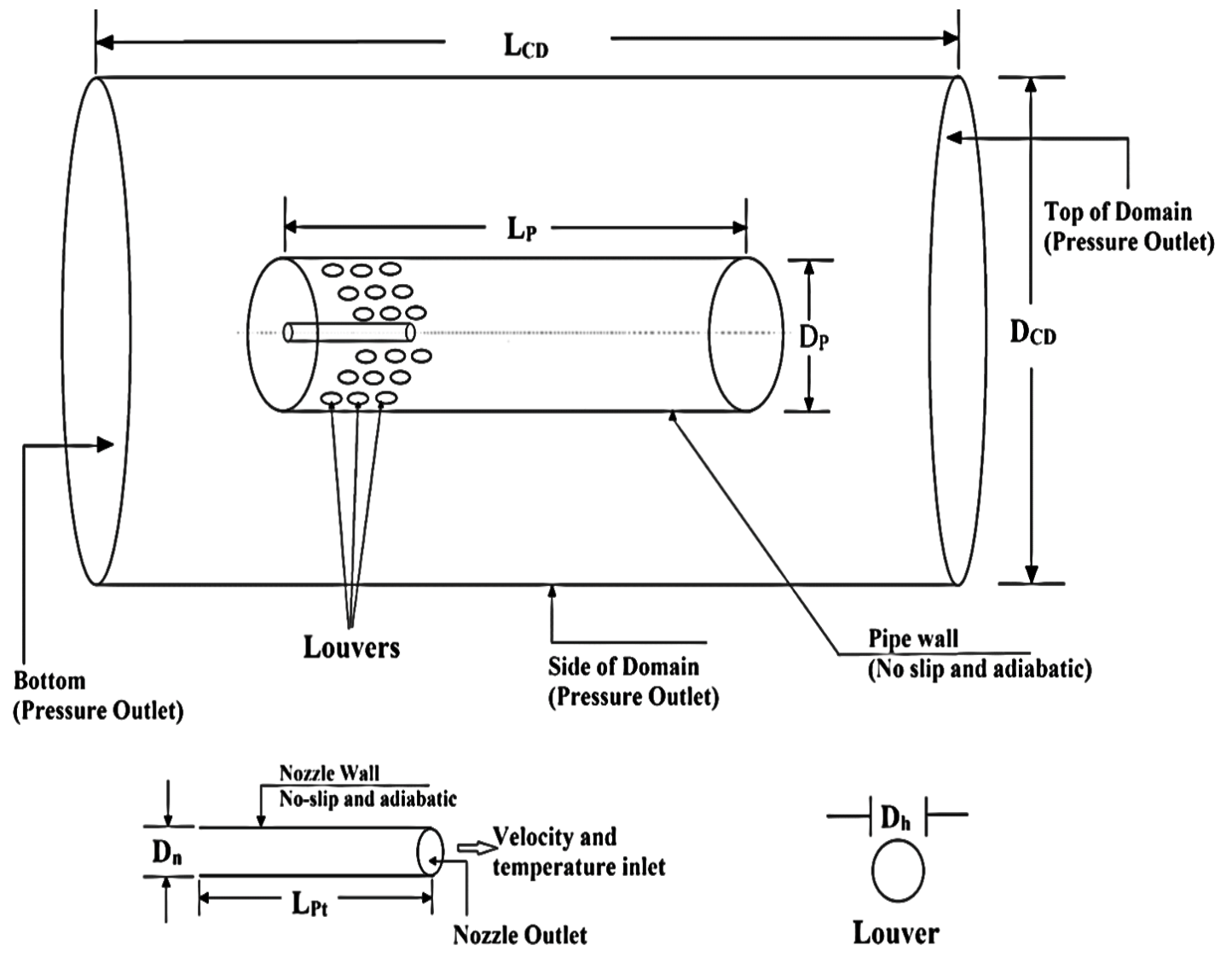

Figure 2. Schematic view of computational domain with applied boundary conditions.

\section{NUMERICAL SOLUTION PROCEDURE}

The computational domain was discretized by using tetrahedral cells. The threedimensional equations for mass, momentum, and energy were discretized over control volume using a finite volume technique to obtain a set of algebraic equations. These algebraic equations were solved by the algebraic multi-grid solver of Fluent 14 by iteration using the proper boundary conditions. The first order upwind scheme was considered for the discretized momentum and turbulent equations. The effect of domain size and number of grids will be discussed in detail separately in the results and discussions.

The SIMPLE algorithm with a Standard scheme was used for the pressure-velocity coupling [6]. The relaxation factors of 0.3 for pressure, 0.7 for momentum, 0.8 for $k$ and $\varepsilon$ and 1 for temperature were used for the convergence of all variables. As the nozzle exit area and louvers opening area were small, fine grids were used at the nozzle entrance and louver openings to get better accuracy. The effect of cell number on the suction rate will be discussed separately in the results and discussion in Figure 6. As the computational 
domain is complicated, therefore, the tetrahedral cells used for the entire computational domain and also numerical analysis conducted by Mishra, Dash [9] revealed that for the cylindrical domain, the results obtained by using tetrahedral cells were close to the experimental values. The convergence criterion for the discretized equations for the whole field residual was set to $10^{-3}$ for all variables except for energy equation which residual level was set to $10^{-6}$.

\section{RESULTS AND DISCUSSION}

\section{Comparison with Other Computations}

The researchers have tried to match the entrainment of air into a confined jet in the cylindrical pipe where the suction from the atmosphere was allowed only from the bottom opening of the pipe close to the nozzle as shown in Figure 3. The ratio $\mathrm{Q}_{\text {suction }} / \mathrm{Q}_{\text {inlet }}$ obtained from the numerical computation using the k- $\varepsilon$ turbulence model was compared with the experiment by Singh, Sundararajan [4] and Pritchard's relation for confined jet as can be seen in Figure 3. The results from the present CFD k- $\varepsilon$ model match well with the analytic solution developed by Prichard, Guy [19] and experiment by Singh, Sundararajan [4].

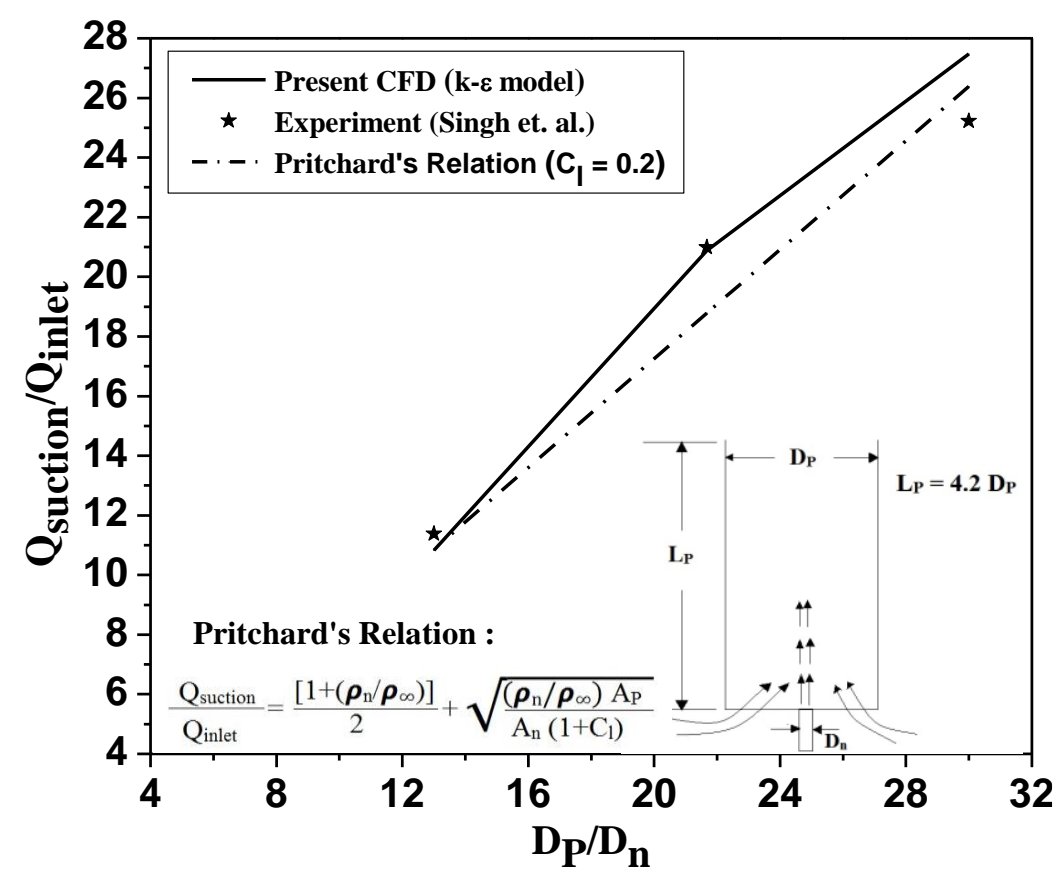

Figure 3. The entrainment ratio as a function of $\mathrm{D}_{\mathrm{P}} / \mathrm{D}_{\mathrm{n}}$, a comparison between the present CFD with Pritchard's relation and experiment (Singh, Sundararajan [4]).

The radial profile of the mean axial velocity of a wall-constraint jet can be seen in Figure 4 . The mean axial velocity $\mathrm{u}(\mathrm{x}, \mathrm{y})$ was normalized by the centreline velocity $\mathrm{u}(\mathrm{x}$, 0 ) and the radial distance was scaled by the jet half width $\left(y_{0.5}\right)$. The jet half-width was defined as the transverse distance from the jet axis to the location where the mean axial velocity $\mathrm{u}(x, y)$ was half of the centreline value $\mathrm{u}(x, 0)$. Singh, Sundararajan [4] and Becker, Hottel [20] proposed that if the velocity profile exhibits self-similarity, then the axial velocity profile is reduced into a single curve. Singh, Sundararajan [4] performed an experimental investigation of a wall constrained bottom opening vertical pipe, where 
the air is allowed to entrain from the bottom and an empirical correlation developed by Becker, Hottel [20] for a mixing flow turbulent jet which is given by $\frac{u}{U c}=\exp \left[-0.693\left(R_{u}\right)^{1.82}\right]$. From Figure 4, it can be seen that the results from the present CFD k- $\varepsilon$ model for radial velocity profiles match well with the experimental results from Singh, Sundararajan [4] and empirical relation developed by Becker, Hottel [20].

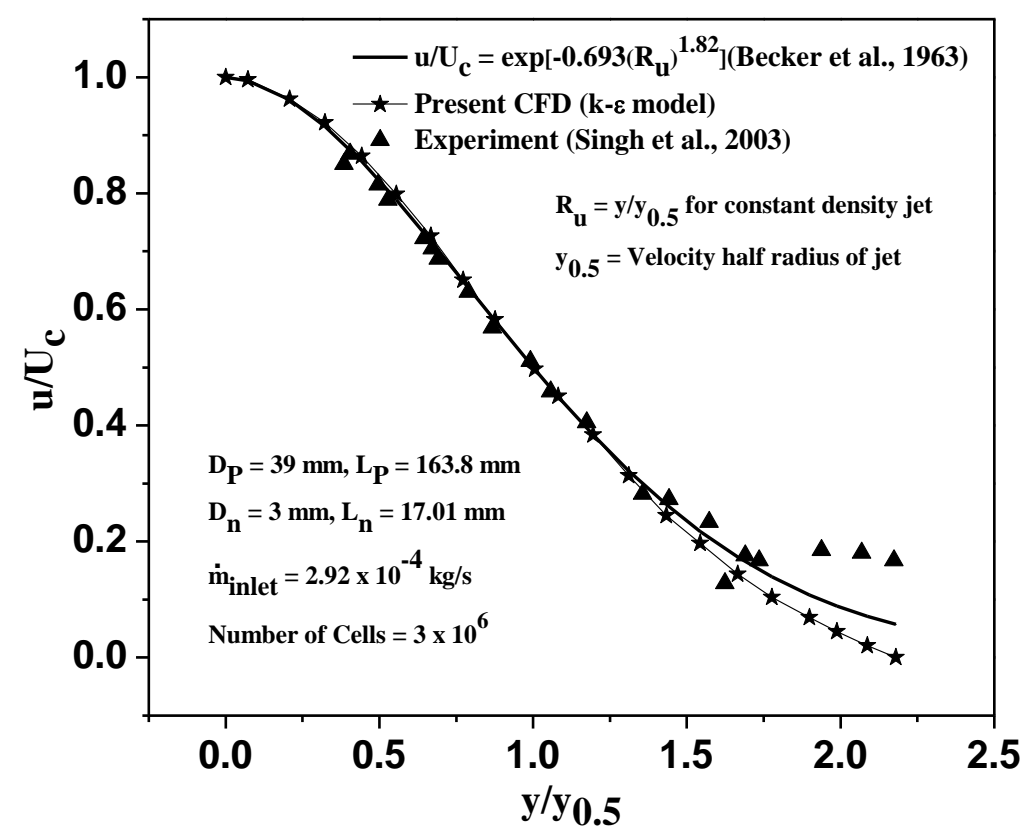

Figure 4. Radial profile of axial velocity of a confined jet cylindrical pipe: A comparison of the present CFD model with the empirical correlation developed by

Becker, Hottel [20] and existing experiment (Singh, Sundararajan [4]).

\section{Effect of Domain Size on the Air Suction Rate}

Figure 5 shows the effect of the size of the computational domain on the suction rate. For each case, the pipe diameter and length were fixed at $0.2 \mathrm{~m}$ and $1 \mathrm{~m}$, while the diameter of the computational domain was varied from 4 to 8 times the pipe diameter and its length was varied from two to four times the pipe length. All the other parameters were kept constant as can be read from Figure 5. The pressure outlet boundary condition was used on all the faces of the computational domain. The top surface of the computational domain allowed the air mass to flow out of the pipe, while other surfaces of the domain were used to allow the atmospheric air to come into the pipe from different locations on the pipe. The pressure outlet boundary was the only choice for the boundary condition for these types of cases. It can be clearly seen that the domain size has no appreciable effect on the air suction rate. As the pressure outlet boundary condition was given at the outer periphery of the domain, the velocity of the fluid at that point was zero and the pressure was at the atmospheric pressure. Keeping in mind the computational accuracy and minimum time size of the domain were chosen [9], the present case considered $2 \mathrm{~m}$ length and $0.8 \mathrm{~m}$ diameter computational domain for a pipe size $1 \mathrm{~m} \times 0.2 \mathrm{~m}$ diameter. 


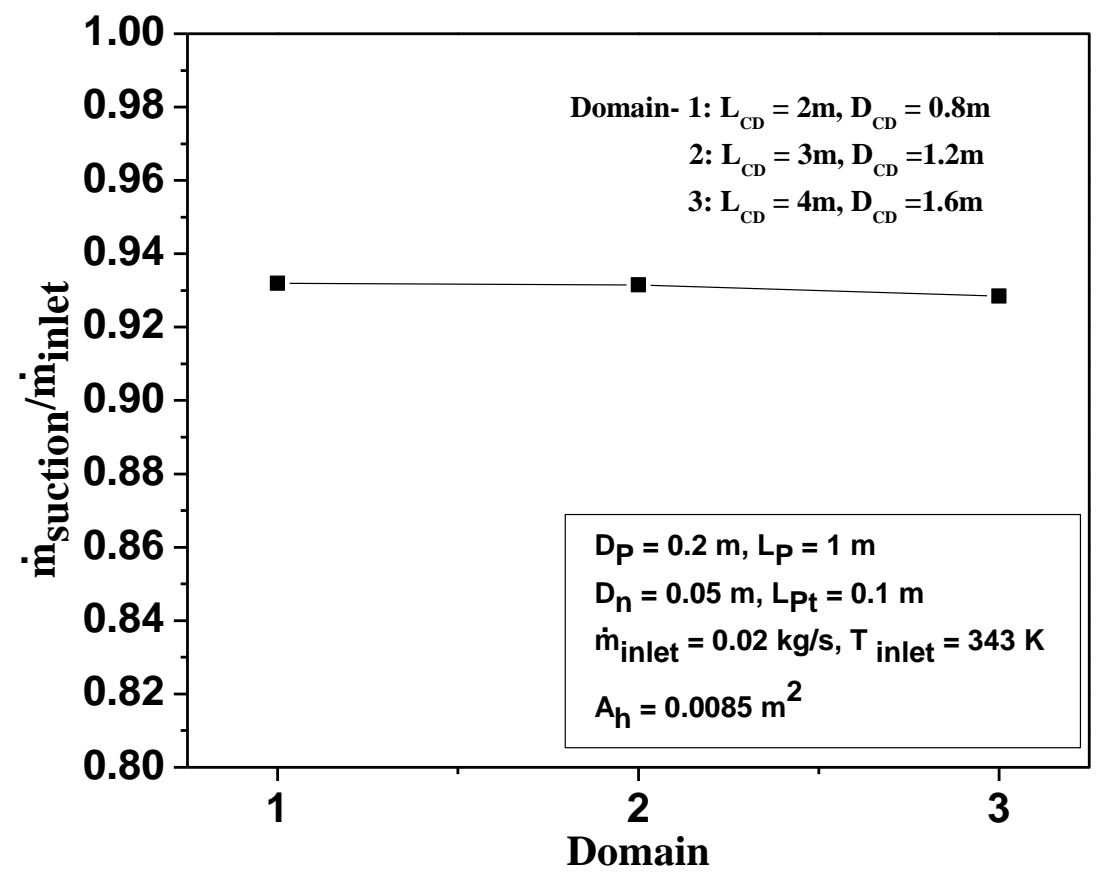

Figure 5. Effect of the domain size on suction rate.

\section{Effect of the number of cells on the air suction rate}

The numerical investigation started with a pipe diameter $\left(D_{P}\right)$ of $0.2 \mathrm{~m}$ and length $\left(L_{P}\right) 1$ $\mathrm{m}$ while the surrounding domain diameter $\left(\mathrm{D}_{\mathrm{CD}}\right)$ and length $\left(\mathrm{L}_{\mathrm{CD}}\right)$ were taken as $0.8 \mathrm{~m}$ and $2 \mathrm{~m}$, respectively. The nozzle diameter $\left(\mathrm{D}_{\mathrm{n}}\right)$ and protruding length $\left(\mathrm{L}_{\mathrm{Pt}}\right)$ of the nozzle were taken as $0.05 \mathrm{~m}$ and $0.1 \mathrm{~m}$. The circumference of the pipe was cut with 12 circular louvers per row $\left(D_{h}=0.03 \mathrm{~m}, A_{h}=0.0085 \mathrm{~m}^{2}\right)$. Only 1 row of the louver was used to study the effect of cell numbers on the air suction rate. The number of rows of the louver was varied after getting an optimum grid interval size and its effect will be shown later in the study.

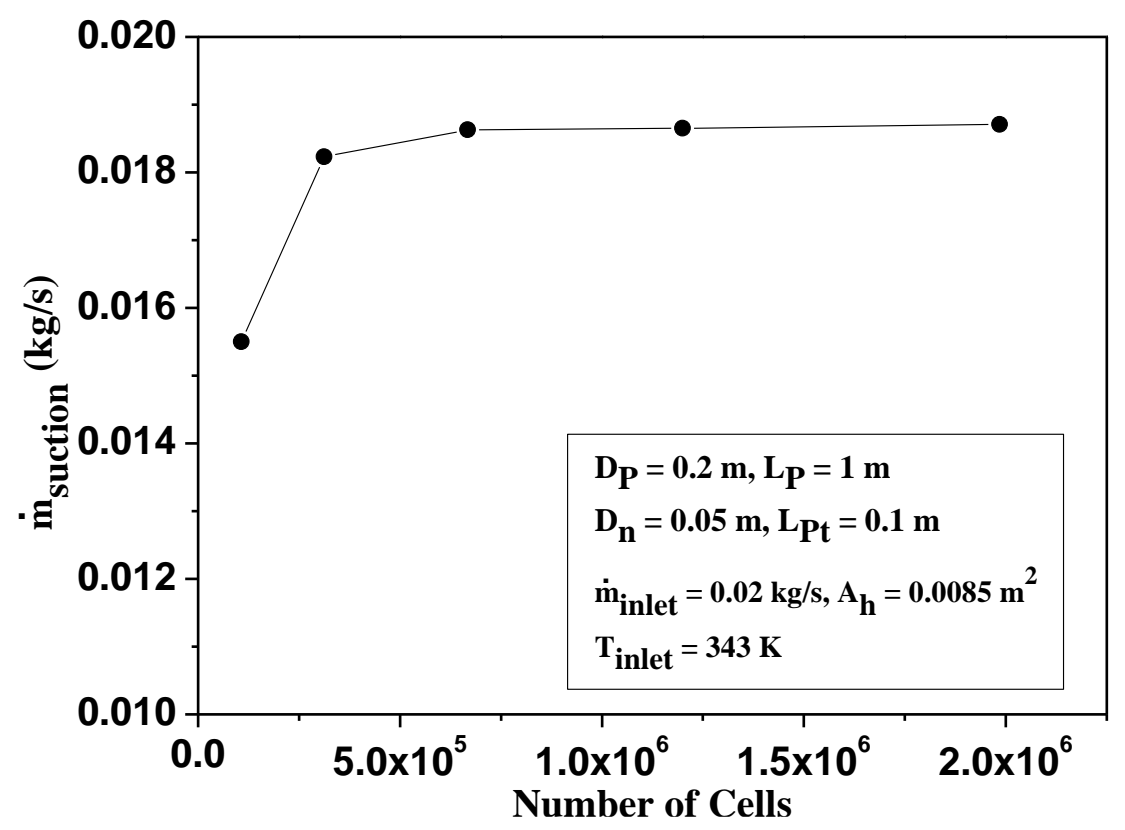

Figure 6. Effect of number of cells on air suction rate. 
The distance between each row was maintained at $0.05 \mathrm{~m}$. The air flow rate of $0.02 \mathrm{~kg} / \mathrm{s}$ was maintained through the nozzle. This analysis was initiated by keeping all the other parameters constant. The number of cells was varied from 100,000 to 2,000,000. The air suction rate almost became constant from 600,000 numbers of cells. Figure 6 shows the effect of the number of cells on the air suction rate. Thus, the mesh which gave 600,000 numbers of cells was considered for performing further computations.

\section{Effect of Louvers Opening Area on the Air Suction Rate}

Figure 7 shows the effect of increasing louver opening area on the air suction rate as a function of nozzle fluid temperature. The simulations were carried out for the louvers opening area of $0.0085 \mathrm{~m}^{2}, 0.017 \mathrm{~m}^{2}, 0.0255 \mathrm{~m}^{2}, 0.034 \mathrm{~m}^{2}, 0.0425 \mathrm{~m}^{2}, 0.051 \mathrm{~m}^{2}, 0.0595$ $\mathrm{m}^{2}, 0.068 \mathrm{~m}^{2}$, and $0.076 \mathrm{~m}^{2}$. The nozzle flow rate was kept constant at $0.02 \mathrm{~kg} / \mathrm{s}$. The louver opening area was increased by cutting the louvers around the periphery. As shown in Figure 1 the rows of the louvers were placed symmetrically one after the other around the periphery. The louvers were placed at a location close to the nozzle so that the suction effect can be enhanced [13]. The distance between each row was maintained at $0.5 \mathrm{~m}$. The nozzle diameter, nozzle protruding length, pipe diameter, and pipe length were kept constant at $0.05 \mathrm{~m}, 0.1 \mathrm{~m}, 0.2 \mathrm{~m}$, and $1 \mathrm{~m}$.

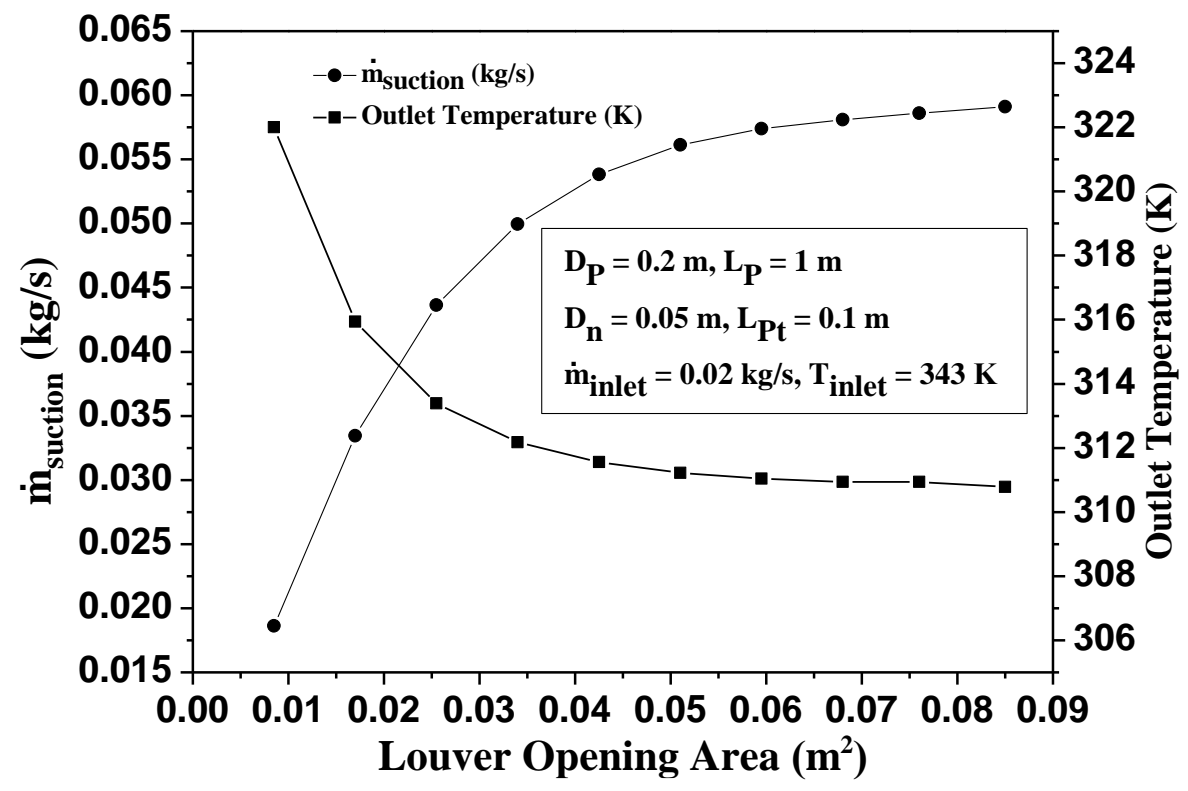

Figure 7 Effect of louvers opening area on the air suction rate and pipe outlet temperature

Figure 7 shows that with the increase in the louvers opening area the air suction rate also increased. The sucked cold air was mixed with the hot air of the nozzle; as a result, the pipe exit temperature decreased [13]. It was evident from the plot that as the suction rate increased the outlet temperature was reduced. When the louvers opening area was doubled, the air suction rate increased by 1.8 times whereas by increasing the louver opening area by six times, the air suction rate was increased by three times. The lowpressure zone created inside the mixing pipe was close to the nozzle exit. This means the louvers placed close to the nozzle exit was more effective in sucking the air compared to the louvers placed away from the nozzle exit. Thus, the opening area was doubled which means two rows of louvers were placed close to the nozzle exit putting more number of 
louvers after it has less effect on the suction as it was away from the nozzle exit. It can be seen from Figure 7 that increasing the louver opening area beyond $0.051 \mathrm{~m}^{2}$ had no appreciable effect on the increase of air suction rate. This occurs because the louvers located towards the top of the pipe do not create enough low pressure inside the pipe for the atmospheric air to be sucked in. The atmospheric pressure was imposed on the top surface of the pipe, so the louvers placed close to the top will not be very effective and if the louvers are placed in the bottom half of the pipe, i.e., close to the nozzle, the air suction is more effective. The low-pressure zone was created due to the high-velocity jet of hot air sucked the atmospheric cold air and both the stream mixed together inside the pipe and travelled upward due to the kinetic energy of the high-velocity jet and left the top surface of the pipe.

\section{Effect of Number of Nozzles on the Air Suction Rate}

The numerical investigation was performed by using the multiple nozzles to study its effect on the suction rate. Instead of a single nozzle, multiple nozzles were used where the number of nozzles was increased to 2, 4 and 6 . They were placed at a constant pitch circle diameter $\left(D_{p d}=0.1 \mathrm{~m}\right)$ as shown in Figure 8 in contrast to the single nozzle which was located at the centre of the pipe. The mass flow rate was maintained constant at 0.02 $\mathrm{kg} / \mathrm{s}$ for all the cases of single and multiple nozzles.

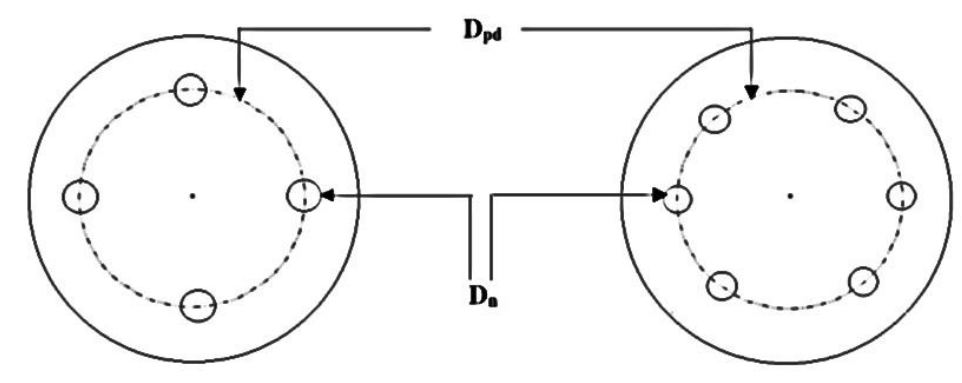

Figure 8. Multiple nozzles on the pitch circle diameter.

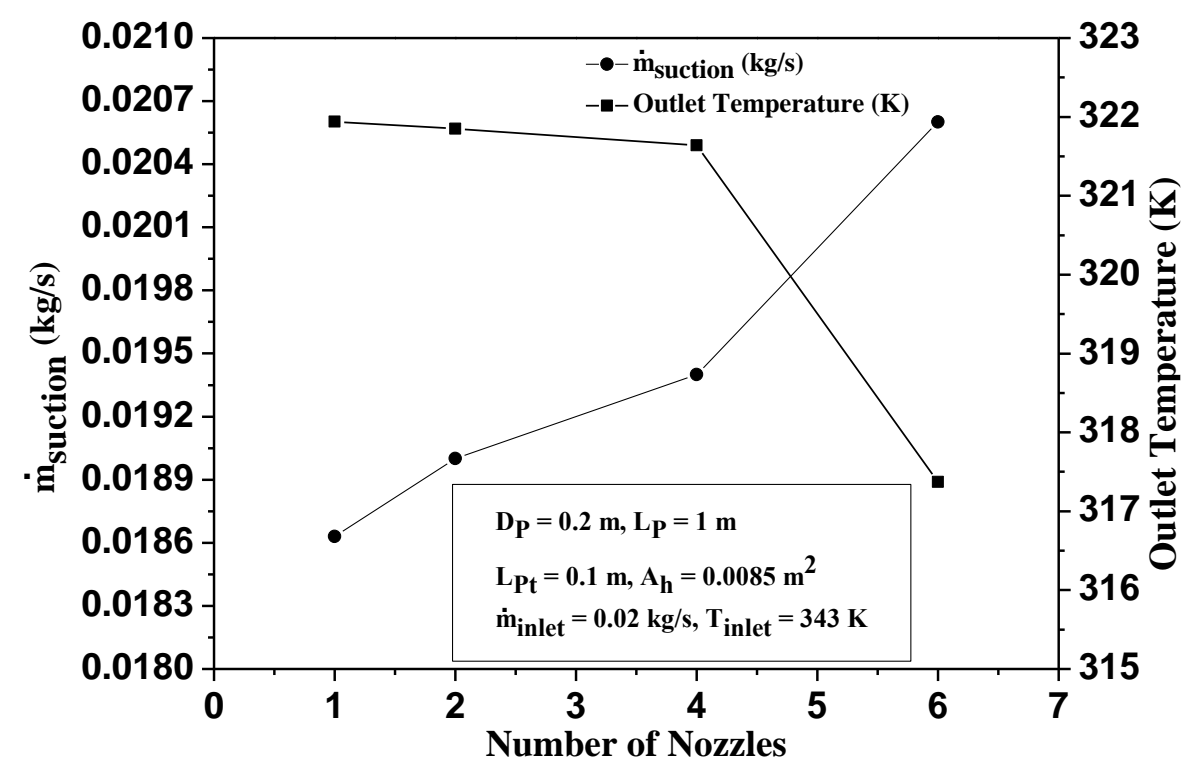

Figure 9. Effect of the number of nozzles on air suction rate and pipe outlet temperature. 
The effect of the mass suction rate and pipe exit temperature as a function of the nozzle number is shown in Figure 9. It can be seen from the plot that the air suction rate is increased with the increasing number of nozzle and dropping of the outlet temperature due to the better mixing of hot air from the nozzles and cold air sucked inside the pipe. The reason is that in the case of a single nozzle, low-pressure was created at the centre of the pipe where in multiple nozzles the low-pressure was created throughout the pipe which sucks more air from the surroundings [13]. It was also observed that by increasing the nozzle number to more than six the exit temperature dropped sharply. This clearly signifies that by increasing the nozzle number the mixing of hot fluid jets and sucked cold air through the louvers improved significantly and the exit temperature dropped considerably.

\section{Effect of Nozzle Protrusion on the Air Suction Rate}

Figure 10 shows the effect of nozzle protruding length on the air suction rate and nozzle exit temperature. The pipe diameter and length, nozzle diameter, mass flow rate, louvers opening area and inlet temperature of nozzle fluid were kept constant. The air suction rate increased as the protrusion was increased from 0 to $0.75 \mathrm{~m}$ and decreased with the increase in the protrusion. The low-pressure was created by the high-velocity jet close to the nozzle tip, so the louvers close to the nozzle were more effective in sucking the air from the surrounding. Therefore, the optimum protrusion for the nozzle was found to be at $0.075 \mathrm{~m}$ because at this point the air suction rate was at the maximum and the outlet temperature of the nozzle fluid was at the minimum. The air suction rate decreased after protruding the nozzle beyond $0.075 \mathrm{~m}$ due to the fact that the nozzle was unable to create enough low-pressure around the louvers. This was observed because as the nozzle moved towards the exit of the pipe, it approached the atmospheric pressure, so the high-velocity air jet from the nozzle did not create enough low-pressure which resulted in the low air suction rate. It can be concluded from this experiment that an optimum protrusion for the nozzle was found for the maximum air suction through the louvers in the pipe.

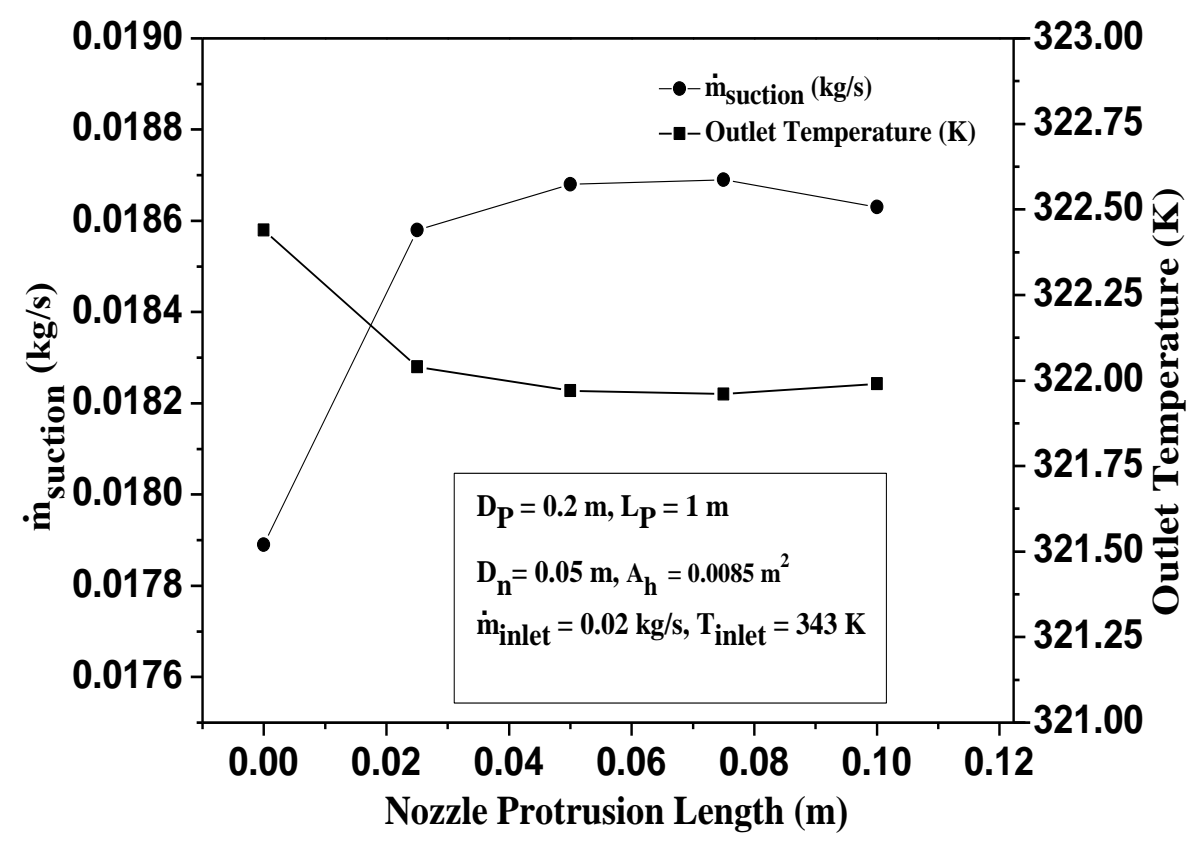

Figure 10. Effect of nozzle protrusion length as a function of the air suction rate and pipe outlet temperature. 


\section{Effect of Change in Pipe Diameter on the Air Suction Rate}

Figure 11 shows the effect of a change in the pipe diameter normalised by the nozzle diameter on the air suction rate. A shown in the plot, the size of the computational domain, louver opening area, pipe length, nozzle diameter and protrusion length mass flow rate and inlet temperature of nozzle fluid were kept constant. The pipe diameter was increased from $0.15 \mathrm{~m}$ to $0.2 \mathrm{~m}$. From Figure 11, the increase in pipe diameter decreased the air suction rate due to which the outlet temperature of the nozzle fluid increases. This indicates that the low-pressure created by the central hot jet was unable to suck air when the diameter of the mixing pipe was increased and due to that the mass suction of the air decreased and outlet temperature increased [5].

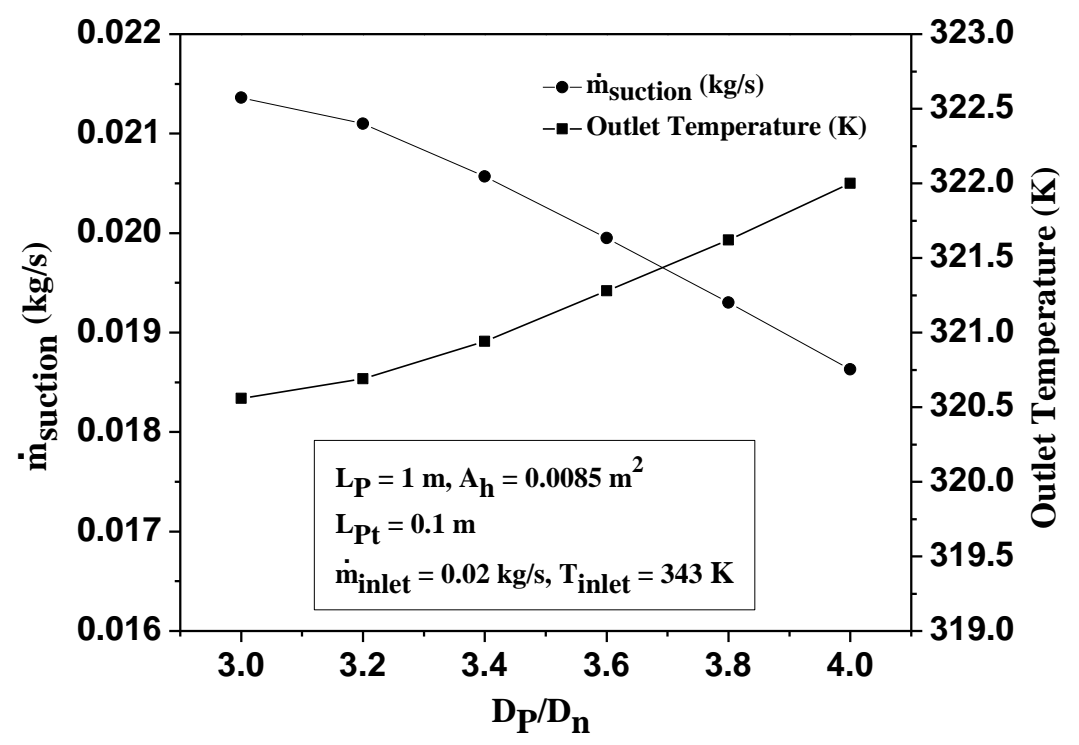

Figure 11. Effect of pipe diameter normalized by nozzle diameter as a function of pipe outlet temperature on the air suction rate.

\section{CONCLUSIONS}

The numerical investigation of the parametric study of the air suction rate through the louvers of a cylindrical pipe done by solving the conservation equations of mass, momentum, and energy with two equation based k- $\varepsilon$ turbulence model has been reported in this paper. The conclusions that can be drawn from the present investigation are as follows:

- The air suction rate increased with the increase in the louver opening area which thereby decreased the outlet temperature of the nozzle fluid. From the CFD analysis, it became clear that the maximum suction effect was observed when the louvers were placed in the bottom half of the pipe and closer to the nozzle. The air suction rate strongly depends on the louver opening area.

- The air suction rate was increased up to 1.1 times by using six nozzles as compared to a single nozzle.

- The nozzle protrusion in the pipe should be $0.075 \mathrm{~m}$ for the maximum air suction.

- For a given nozzle flow rate and louvers opening area, it was found that the air suction rate was maximum when the pipe diameter was three times the nozzle diameter i.e., for the nozzle diameter of $0.05 \mathrm{~m}$, the pipe diameter of $0.15 \mathrm{~m}$ gave the maximum air suction rate. 


\section{ACKNOWLEDGEMENT}

The authors are grateful to the Birla Institute of Technology, Mesra, for providing the diesel engine data and the computational support (Fluent 14) to carry out the numerical analysis.

\section{REFERENCES}

[1] Ricou FP, Spalding D. Measurements of entrainment by axisymmetrical turbulent jets. Journal of fluid mechanics. 1961;11:21-32.

[2] Hill B. Measurement of local entrainment rate in the initial region of axisymmetric turbulent air jets. Journal of fluid mechanics. 1972;51:773-9.

[3] Han D, Mungal M. Direct measurement of entrainment in reacting/nonreacting turbulent jets. Combustion and flame. 2001;124:370-86.

[4] Singh G, Sundararajan T, Bhaskaran K. Mixing and entrainment characteristics of circular and noncircular confined jets. Journal of Fluids Engineering. 2003;125:835-42.

[5] Mishra DP, Dash SK. Prediction of entrance length and mass suction rate for a cylindrical sucking funnel. International Journal for Numerical Methods in Fluids. 2010;63:681-700.

[6] Mishra DP, Dash SK. Numerical investigation of air suction through the louvers of a funnel due to high velocity air jet. Computers \& Fluids. 2010;39:1597-608.

[7] Barik AK, Dash SK, Patro P, Mohapatra S. Experimental and numerical investigation of air entrainment into a louvred funnel. Applied Ocean Research. 2014;48:176-85.

[8] Singh G. Entrainment and mixing studies for a variable density confined jet. Numerical Heat Transfer: Part A: Applications. 1999;35:205-24.

[9] Mishra DP, Dash SK, Kishan PA. Isothermal jet suction through the lateral openings of a cylindrical funnel. Journal of Ship Research. 2010;54:268-80.

[10] Barik AK, Dash SK, Guha A. Entrainment of air into an infrared suppression (IRS) device using circular and non-circular multiple nozzles. Computers \& Fluids. 2015;114:26-38.

[11] Barik AK, Dash SK, Guha A. Experimental and numerical investigation of air entrainment into an infrared suppression device. Applied Thermal Engineering. 2015;75:33-44.

[12] Barik AK, Dash SK, Guha A. New correlation for prediction of air entrainment into an Infrared Suppression (IRS) device. Applied Ocean Research. 2014;47:303-12.

[13] Mishra DP, Dash SK. Maximum air suction into a louvered funnel through optimum design. Journal of Ship Research. 2012;56:1-11.

[14] Andwari A, Aziz A, Said M, Latiff Z, Ghanaati A. Influence of hot burned gas utilization on the exhaust emission characteristics of a controlled auto-ignition two-stroke cycle engine. International Journal of Automotive and Mechanical Engineering. 2015;11:2396.

[15] Akasyah M, Mamat R, Abdullah A, Aziz A, Yassin H. Effect of ambient temperature on diesel-engine combustion characteristics operating with alcohol fuel. International Journal of Automotive and Mechanical Engineering. 2015;11:2373. 
[16] Hamada KI, Rahman M. An experimental study for performance and emissions of a small four-stroke SI engine for modern motorcycle. International Journal of Automotive and Mechanical Engineering. 2014;10:1852.

[17] Hamada KI Rahman MM, Ramasamy D, Noor MM, Kadirgama K. Numerical investigation of in-cylinder flow characteristics of hydrogen-fuelled internal combustion engine. Journal of Mechanical Engineering and Science 2016;10:1792-802.

[18] Mohd Noor CW MR, Najafi G, Mat Yasin MH, Ihsan CK, Noor MM. Prediction of marine diesel engine performance by using artificial neural network Model. Journal of Mechanical Engineering and Sciences. 2016;10:1917-30.

[19] Prichard R, Guy J, Conner N. Industrial gas utilization. New Providence (NJ): Bowker. 1977.

[20] Becker H, Hottel H, Williams G. Mixing and flow in ducted turbulent jets. Symposium (International) on Combustion: Elsevier; 1963. p. 7-20.

\section{NOMENCLATURE}

$A_{h} \quad$ Louvers opening area

$C_{1 \varepsilon} \quad$ Constant of value 1.44

$C_{2 \varepsilon} \quad$ Constant of value 1.92

$D_{C D} \quad$ Diameter of computational domain

$D_{P} \quad$ Diameter of pipe

$D_{n} \quad$ Diameter of nozzle

$D_{h} \quad$ Diameter of circular louver

$D_{p d} \quad$ Pitch circle diameter

$D_{k} \quad=\frac{\partial}{\partial x_{j}}\left[\left(\mu+\frac{\mu_{t}}{\sigma_{k}}\right) \frac{\partial k}{\partial x_{j}}\right]$

$D_{\varepsilon} \quad=\frac{\partial}{\partial x_{j}}\left[\left(\mu+\frac{\mu_{t}}{\sigma_{\varepsilon}}\right) \frac{\partial \varepsilon}{\partial x_{j}}\right]$

$L_{C D} \quad$ Length of computational domain

$L_{P} \quad$ Length of pipe

$L_{P t} \quad$ Protruding length of nozzle

$\dot{m}_{\text {inlet }}$ Mass flow rate through the nozzle

$\dot{m}_{\text {suction }}$ Air suction rate through louvers

$k \quad$ Turbulent kinetic energy

$P \quad$ Pressure

$\operatorname{Pr} \quad \mathrm{v} / \alpha$
$P r_{t} \quad$ Turbulent Prandtl number

$R e_{n}$ Reynolds number based on nozzle,

$$
\rho V_{n} D_{n} / \mu
$$

$T \quad$ Temperature

$U \quad$ Velocity

$V_{n} \quad$ Velocity at nozzle exit

Greek Symbols

$v \quad$ Kinematic Viscosity

$\rho \quad$ Density

$\mu \quad$ Shear viscosity

$\mu_{t} \quad$ Turbulent viscosity

$\varepsilon \quad$ Dissipation rate

$\sigma_{k} \quad$ Turbulent Prandtl number for k

$\sigma_{\varepsilon} \quad$ Turbulent Prandtl number for $\varepsilon$

$\phi \quad$ Scalar variable either $\mathrm{k}$ or $\varepsilon$

$\alpha \quad$ Thermal diffusivity

Subscripts

n Nozzle

$\infty \quad$ Free stream 